\title{
Cytotoxicity of ZnO Paper against Cancer Cells
}

\author{
Su-Yu Liao, ${ }^{1}$ Jing-Jenn Lin, ${ }^{2}$ Congo Tak-Shing Ching, ${ }^{3 *}$ and You-Lin $\mathrm{Wu}^{1 * *}$ \\ ${ }^{1}$ Department of Electrical Engineering, National Chi Nan University, \\ 301 University Road, Puli, Nantou 54561, Taiwan \\ ${ }^{2}$ Department of Applied Materials and Optoelectronic Engineering, National Chi Nan University, \\ 1 University Road, Puli, Nantou 54561, Taiwan \\ ${ }^{3}$ Graduate Institute of Biomedical Engineering, National Chung Hsing University, \\ 145 Xingda Road., South Dist., Taichung 40227, Taiwan
}

(Received June 30, 2021; accepted August 27, 2021)

Keywords: cancer cells, cytotoxicity, Iressa, Staurosporine, $\mathrm{ZnO}$ paper

Paper incorporated with $\mathrm{ZnO}$ nanostructures (called $\mathrm{ZnO}$ paper) is a flexible substrate material with applications in many areas including UV detectors and gas sensors. In this work, we tested the cytotoxicity of $\mathrm{ZnO}$ paper against cancer cells. The $\mathrm{ZnO}$ paper was placed in culture media of different cancer cell lines including A549, H1299, and WI38 with and without the targeted anti-lung cancer drugs Iressa and Staurosporine, and cell viability was determined. We found that $\mathrm{ZnO}$ nanoparticles were cytotoxic to all the cell lines examined, and cell viability was further reduced by increasing the deposition time of these nanoparticles. In addition, cytotoxicity was enhanced when both the $\mathrm{ZnO}$ paper and the anticancer drugs were present in the culture media. Our experimental results indicate that $\mathrm{ZnO}$ paper can be used for cytotoxicity test and the development of future novel anticancer drugs.

\section{Introduction}

Among nanomaterials, $\mathrm{ZnO}$ has attracted a high degree of attention in biomedical applications because its surface is generally terminated with hydroxyl groups and can be easily functionalized through surface modification. ${ }^{(1-3)} \mathrm{In}$ addition, $\mathrm{ZnO}$ is biocompatible and biodegradable, and its $\mathrm{Zn}^{2+}$ ion constituent is an indispensable trace element in adults. Furthermore, $\mathrm{ZnO}$ nanoparticles have been found to have antibacterial properties ${ }^{(4,5)}$ and inherent toxicity towards cancer cells ${ }^{(6,7)}$ and are highly selective. ${ }^{(3,8,9)}$ For example, it has been found that $\mathrm{ZnO}$ nanoparticles have a cytotoxic effect on several human glioma cell lines but no effect on normal human astrocytes. ${ }^{(10)}$ It has also been shown that $\mathrm{ZnO}$ nanoparticles can induce cell death in breast and prostate cancer cell lines without adversely affecting normal breast and prostate cells..$^{(11)}$

Paper has been considered for the development of flexible electronics as a pliable substrate and an alternative to plastic polymers (e.g., polyamide and polyesters). It has been reported that $\mathrm{ZnO}$ paper can be used in sensors and detectors, such as strain sensors, ${ }^{(12)}$ oxygen sensors, ${ }^{(13)}$ and UV detectors. ${ }^{(14)}$ It has also been used in studies of antibacterial properties. ${ }^{(15,16)}$ However,

\footnotetext{
*Corresponding author: e-mail: tsching@nchu.edu.tw

**Corresponding author: e-mail: ylwu@ncnu.edu.tw

https://doi.org/10.18494/SAM.2021.3511
} 
there have been no reports on the use of $\mathrm{ZnO}$ paper for cancer cell cytotoxicity tests. In this work, we evaluate the cytotoxicity of $\mathrm{ZnO}$ paper with and without added anticancer drugs against cancer cells.

\section{Materials and Methods}

\subsection{ZnO paper preparation}

Zinc acetate dihydrate was chemically reduced to deposit $\mathrm{ZnO}$ nanoparticles on the surface of cellulose paper. First, a solution of $0.01 \mathrm{M}$ zinc acetate dihydrate dissolved in $100 \mathrm{~mL}$ of isopropanol was prepared at a temperature of $50{ }^{\circ} \mathrm{C}$ and stirred for $90 \mathrm{~min}$. A $130 \mathrm{~mL}$ isopropanol solution mixed with $0.02 \mathrm{M}$ sodium hydroxide was also prepared at $60{ }^{\circ} \mathrm{C}$ and stirred for $120 \mathrm{~min}$. The two solutions were mixed after they had cooled to room temperature, and a piece of cellulose paper was placed at the bottom of the combined solution for either 30 or $50 \mathrm{~h}$ to allow the $\mathrm{ZnO}$ nanoparticles to deposit on the surface. The $\mathrm{ZnO}$ paper was then subjected to 15 min of baking at $100{ }^{\circ} \mathrm{C}$. X-ray diffraction (XRD) analysis was used to characterize the crystal structure, and scanning electron microscopy (SEM) was performed to observe the morphology of the $\mathrm{ZnO}$ nanoparticles deposited on the cellulose paper.

\subsection{Cell culture}

Prior to culturing the cell lines on the surface of the cellulose paper, the cell lines were grown separately in their culture media. Specifically, WI38 cells were cultured in $5 \mathrm{~mL}$ of Eagle's minimum essential medium (MEM) containing 10\% fetal bovine serum (FBS) supplemented with $10 \mathrm{~mL} / \mathrm{L}$ penicillin/streptomycin and $10 \mathrm{~mL} / \mathrm{L}$ L-glutamine (Life Technologies, Inc., Frederick, MD, U.S.). A549 and H1299 cell lines (obtained from the American Type Culture Collection, Manassas, VA, U.S.) were grown in $5 \mathrm{~mL}$ of Dulbecco's modified Eagle's medium (DMEM) containing 10\% FBS supplemented with penicillin (50 units/mL) and streptomycin $(50 \mu \mathrm{g} / \mathrm{mL})$. All cell lines were cultured in an incubator under $5 \% \mathrm{CO}_{2}$ at $37{ }^{\circ} \mathrm{C}$. After the cells had obtained a density of $2 \times 10^{7} \mathrm{cells} / \mathrm{cm}^{2}$ (approximately three days for the cancer cell lines and seven days for the normal cells), we seeded $1 \times 10^{4}$ cells of each cell type into a 12-well dish using a micropipette. We then added $2 \mathrm{~mL}$ of its culture medium into each well (MEM for WI38 cells and DMEM for A549 and H1299 cells).

\subsection{Cytotoxicity assay}

After $24 \mathrm{~h}$ cell culture in an incubator under $5 \% \mathrm{CO}_{2}$ at $37{ }^{\circ} \mathrm{C}$, the $\mathrm{ZnO}$ paper was placed in the 12-well culture dish with the addition of either of the anticancer drugs Iressa and Staurosporine or the medium of the cells as a control. Since the two anticancer drugs target different intracellular pathways, the effective dose depends on the type of cancer cell being targeted. ${ }^{(17,18)}$ Iressa is an epidermal growth factor receptor (EGFR)-specific kinase inhibitor, whereas Staurosporine is a protein kinase C (PKC) inhibitor. We chose doses of $50 \mu \mathrm{M}$ for Iressa 
and $100 \mathrm{nM}$ for Staurosporine on the basis of previous experiments on the cell-substrate interaction in A549 and H1299 cell lines. ${ }^{(19)}$ The treated cells were then cultured for another $24 \mathrm{~h}$, and a conventional MTT [thiazolyl blue tetrazolium bromide, 3-(4,5-dimethylthiazol-2-yl)2,5-diphenyl tetrazolium bromide] assay was performed to determine the viability of the cells in each well.

\section{Results and Discussion}

The typical surface morphology of the ZnO paper is shown in the SEM image in Fig. 1. No apparent difference in surface morphology could be discerned between the $\mathrm{ZnO}$ papers prepared with deposition times of 30 and $50 \mathrm{~h}$. The nanoparticles deposited on the cellulose fibers are clearly visible in the magnified SEM image. To determine the constituents of the deposited nanoparticles, energy-dispersive X-ray spectroscopy (EDX) analysis was performed, and the results are shown in Fig. 2. A similar EDX spectrum was obtained for the $\mathrm{ZnO}$ paper regardless of the deposition time. In addition, we observed that the main constituents of the deposited nanoparticles were $\mathrm{Zn}$ and $\mathrm{O}$. The $\mathrm{Al}$ peak that appeared in the EDX spectrum was determined to have originated from the substrate holder of the EDX analyzer.
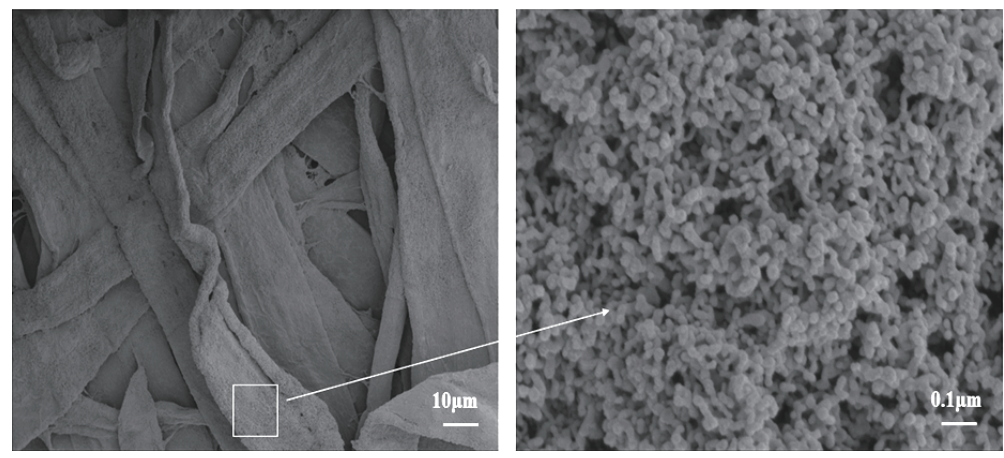

Fig. 1. SEM image and magnification of the $\mathrm{ZnO}$ paper prepared with a deposition time of $50 \mathrm{~h}$.

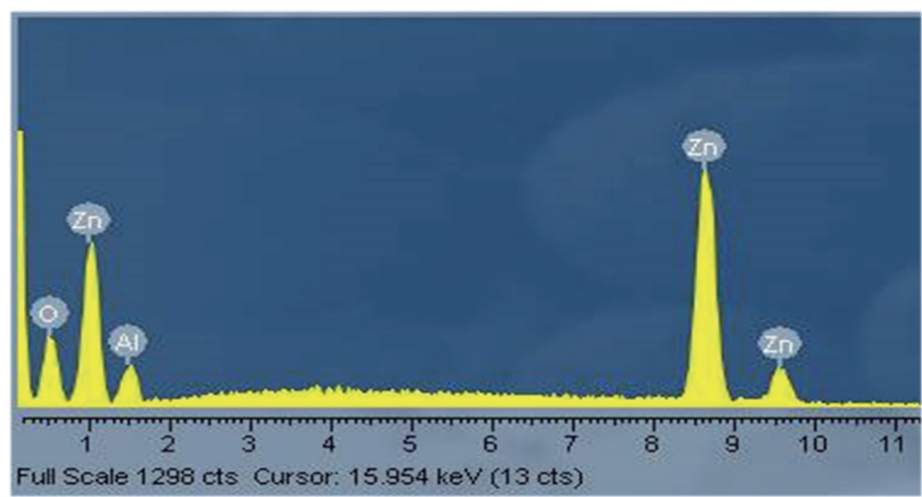

Fig. 2. (Color online) EDX spectrum of the $\mathrm{ZnO}$ paper prepared with a deposition time of $50 \mathrm{~h}$. 
Figure 3 shows the XRD spectra of the cellulose paper and the $\mathrm{ZnO}$ papers prepared by deposition for 30 and $50 \mathrm{~h}$. From the results, we can confirm that the preferential orientations of the deposited $\mathrm{ZnO}$ nanoparticles were (100) and (101). Furthermore, these orientations were found to be independent of the deposition time. The $\mathrm{CaCO}_{3}$ peaks observed in Fig. 3 are from the cellulose paper itself. All of the above data indicate that the $\mathrm{ZnO}$ nanoparticles were indeed deposited on the cellulose paper.

Figure 4 shows the viability of normal WI38 cells cultivated in the culture medium with no treatment, $50 \mu \mathrm{M}$ Iressa, and $100 \mathrm{nM}$ Staurosporine in contact with either uncoated cellulose paper, $30 \mathrm{~h} \mathrm{ZnO}$ paper, or $50 \mathrm{~h} \mathrm{ZnO}$ paper. Interestingly, cell viability was observed to decrease with increasing deposition time of the $\mathrm{ZnO}$ paper, irrespective of the anticancer drug added.

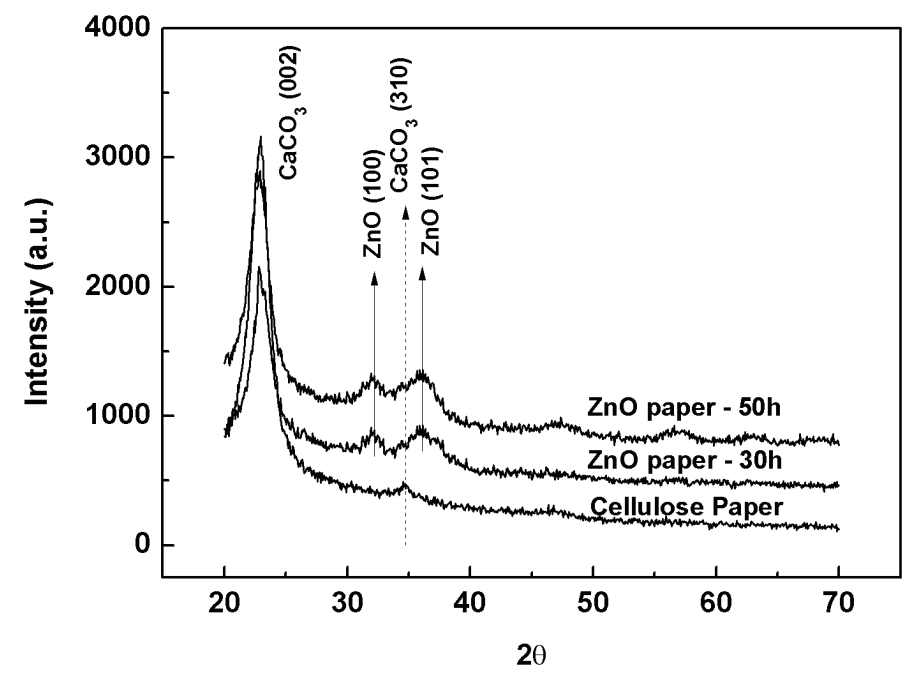

Fig. 3. Results of XRD spectra of pure cellulose paper and $\mathrm{ZnO}$ papers prepared with deposition times of 30 and $50 \mathrm{~h}$.

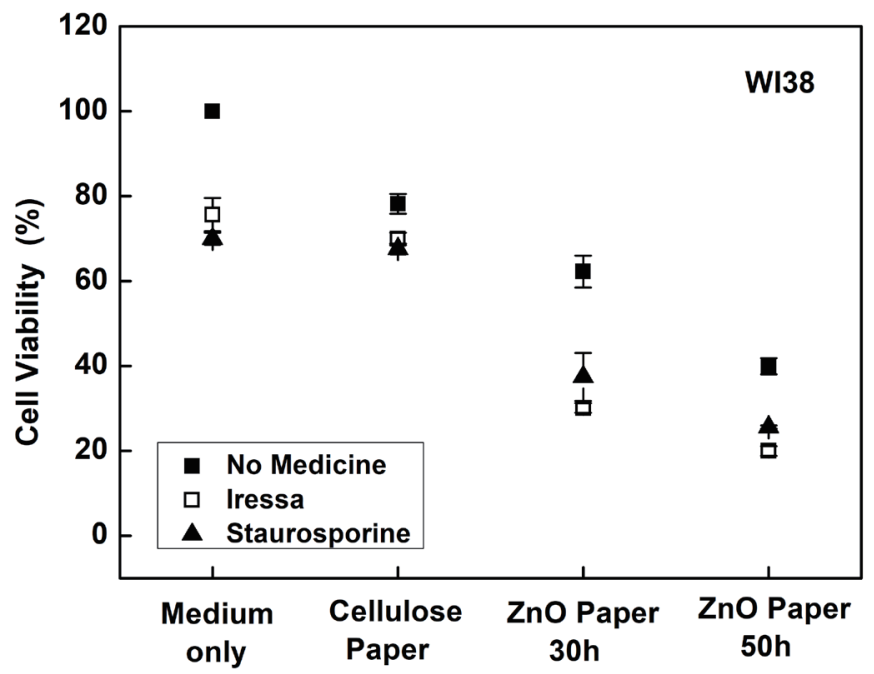

Fig. 4. Viability of WI38 normal cells cultured with no treatment, $50 \mu \mathrm{M}$ Iressa, and $100 \mathrm{nM}$ Staurosporine in contact with either cellulose paper, $30 \mathrm{~h} \mathrm{ZnO}$ paper, or $50 \mathrm{~h} \mathrm{ZnO}$ paper. 
Since increasing the deposition time of the $\mathrm{ZnO}$ paper increases the number of nanoparticles deposited on the cellulose fiber, this result indicates that the $\mathrm{ZnO}$ nanoparticles have a cytotoxic effect on normal WI38 cells, and the higher the number of $\mathrm{ZnO}$ nanoparticles, the greater the level of observed cytotoxicity. Although the actual mechanism of $\mathrm{ZnO}$ nanoparticle cytotoxicity is not completely understood, it is considered to be related to the generation of reactive oxygen species (ROS) involved in metabolic processes. When nanoparticles interact with cells, the cellular defense mechanisms are activated. When the ROS production exceeds the antioxidative defensive capacity of the cell due to the oxidative stress resulting from this metabolic reaction, ${ }^{(20,21)}$ cell damage or even cell death will occur. Increasing the deposition time of the $\mathrm{ZnO}$ paper increases the number of nanoparticles that come into contact with the cells. Therefore, this generates higher oxidative stress and reduces cell viability. It was also observed that adding either Iressa or Staurosporine to the medium lowers the cell viability compared with the case of no treatment, and both drugs displayed similar cytotoxic effects on normal WI38 cells. The viability of the W138 cells in contact with the uncoated cellulose paper was $82 \%$ in the case of no treatment, compared with $73 \%$ after treatment with Iressa and $69 \%$ after treatment with Staurosporine, whereas that of the W138 cells in contact with the $30 \mathrm{~h} \mathrm{ZnO}$ paper was $65 \%$ in the case of no treatment, compared with $31 \%$ after treatment with Iressa and 38\% after treatment with Staurosporine. Therefore, the anticancer drugs affected the viability of normal cells, and adding $\mathrm{ZnO}$ nanoparticles enhanced this cytotoxicity by approximately $25-42 \%$.

Figure 5 shows the viability of the A549 cancer cells cultured with no treatment, $50 \mu \mathrm{M}$ Iressa, and $100 \mathrm{nM}$ Staurosporine in contact with either the cellulose paper, $30 \mathrm{~h} \mathrm{ZnO}$ paper, or $50 \mathrm{~h} \mathrm{ZnO}$ paper. Similar to the results obtained from the normal cell cultures, the cell viability decreased with increasing amount of $\mathrm{ZnO}$ nanoparticles under all the observed conditions. In addition, we found a striking difference in cell viability between the two anticancer drug treatments. It is important to note that Staurosporine was used at a dose of $100 \mathrm{nM}$, whereas Iressa was used at a dose of $50 \mu \mathrm{M}$. Our results show that Staurosporine has a higher degree of

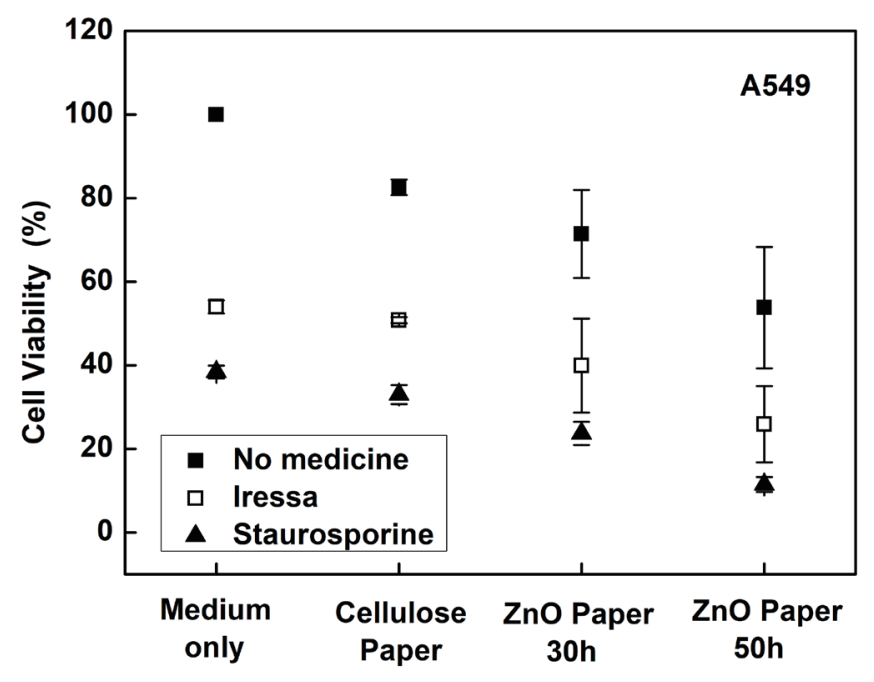

Fig. 5. Viability of A549 cancer cells cultured with no treatment, $50 \mu \mathrm{M}$ Iressa, and $100 \mathrm{nM}$ Staurosporine in contact with either cellulose paper, $30 \mathrm{~h} \mathrm{ZnO}$ paper, or $50 \mathrm{~h} \mathrm{ZnO}$ paper. 
cytotoxicity than Iressa for the A549 cancer cell lines. This may be attributed to the fact that Iressa is an anticancer drug that intracellularly targets the EGFR, whereas Staurosporine specifically targets PKC. It is clear that the PKC inhibitor Staurosporine is more efficient than the EGFR inhibitor Iressa at activating apoptosis in A549 cells. These findings are in agreement with reports from $\mathrm{Wu}$ et al. ${ }^{(22)}$ and Notbohm et al. ${ }^{(23)}$

Figure 6 shows the viability of the H1299 cancer cells cultured with no treatment, $50 \mu \mathrm{M}$ Iressa, and $100 \mathrm{nM}$ Staurosporine in contact with either cellulose paper, $30 \mathrm{~h} \mathrm{ZnO}$ paper, or $50 \mathrm{~h}$ $\mathrm{ZnO}$ paper. Similar to the results from the other cell lines, cell viability decreased as the $\mathrm{ZnO}$ nanoparticle deposition time increased. Interestingly, for the H1299 cells that received no treatment, the cell viability for the $30 \mathrm{~h} \mathrm{ZnO}$ paper was only $44 \%$, more than $50 \%$ lower than that for the uncoated cellulose paper (98\%). This indicates that the H1299 cancer cell line was highly sensitive to the $\mathrm{ZnO}$ nanoparticles. By comparing this result with that of the A549 cells that received no treatment in Fig. 5, it is evident that the cytotoxic effect of the $\mathrm{ZnO}$ nanoparticles is greater for H1299 cells (85\%) than for A549 cells (75\%). This difference in cytotoxicity is believed to be caused by the fact that A549 cells are more malignant than H1299 cells. ${ }^{(24,25)}$ The addition of the anticancer drugs further reduced the cell viability and, similar to the A549 cells, Staurosporine was more cytotoxic than Iressa. Thus, the viability of the cells treated with Staurosporine was lower than that of the cells treated with Iressa. By comparing the post-drug treatments with the cellulose paper and the $50 \mathrm{~h} \mathrm{ZnO}$ paper in Figs. 5 and 6, it is observed that the A549 cell viability decreased from 53 to $27 \%$ after adding Iressa and from 33 to $11 \%$ after adding Staurosporine. For the H1299 cells, the viability was reduced from $\sim 40$ to $\sim 22 \%$ after adding Iressa and from $\sim 25$ to $\sim 13 \%$ after adding Staurosporine. Therefore, there was a total decrease in cell viability of approximately $12-26 \%$ when the anticancer drugs were used in conjunction with the $\mathrm{ZnO}$ nanoparticles.

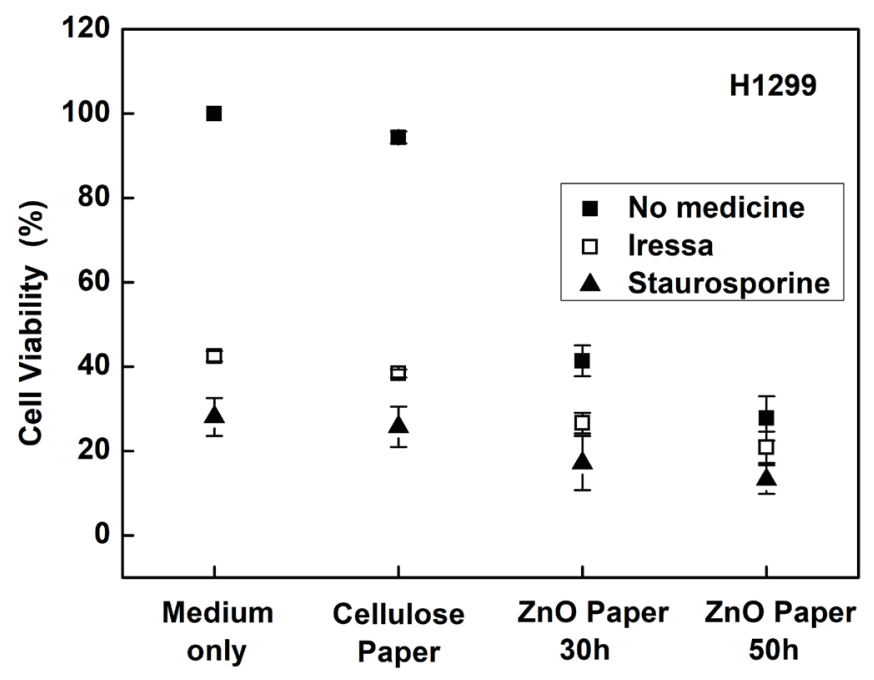

Fig. 6. Viability of H1299 cancer cells cultured with no treatment, $50 \mu \mathrm{M}$ Iressa, and $100 \mathrm{nM}$ Staurosporine in contact with either cellulose paper, $30 \mathrm{~h} \mathrm{ZnO}$ paper, or $50 \mathrm{~h} \mathrm{ZnO}$ paper. 


\section{Conclusion}

In this study, we extended the application of $\mathrm{ZnO}$ paper to the cytotoxic test of WI38 normal cells, as well as A549 and H1299 cancer cell lines. The ZnO paper was prepared by depositing $\mathrm{ZnO}$ nanoparticles on cellulose fibers by the chemical reduction of an isopropanol solution containing zinc acetate dihydrate. The $\mathrm{ZnO}$ paper was placed with the cells in culture media containing different treatments, and the viability of each cell line was subsequently determined by an MTT assay. It was found that when no anticancer drug was present in the culture medium, the $\mathrm{ZnO}$ nanoparticles were cytotoxic to all of the cell lines tested. In addition, the cell viability was found to decrease as the $\mathrm{ZnO}$ paper deposition time increased. It is considered that more oxidative stress is generated if more $\mathrm{ZnO}$ nanoparticles are present, providing a possible explanation for the lower cell viability observed. The cell viability was further reduced in the presence of the anticancer drugs Iressa and Staurosporine, demonstrating that the cytotoxicity of these drugs can be enhanced in the presence of $\mathrm{ZnO}$ nanoparticles. Our experimental results show that the enhanced cytotoxicity of anticancer drugs depends on the deposition time of the $\mathrm{ZnO}$ paper. Although the $\mathrm{ZnO}$ nanoparticles also induce the death of normal cells, enhanced cancer therapy may be achieved by combining an appropriate amount of $\mathrm{ZnO}$ nanoparticles with anticancer drugs. Using $\mathrm{ZnO}$ paper, we have shown that A549 cancer cells are more malignant than H1299 cells, which is in agreement with reported results. ${ }^{(24,25)}$ Our results are also in line with the previous finding that the PKC inhibitor Staurosporine is more efficient than the EGFR inhibitor Iressa at activating the apoptosis of cancer cells. ${ }^{(22,23)}$ In conclusion, we have successfully conducted a test on the cytotoxicity of $\mathrm{ZnO}$ paper. Our findings suggest that it can be utilized as an efficacy detector and an alternative platform to test cellular toxicity for the development of future anticancer drugs.

\section{Acknowledgments}

This work was supported in part by the Ministry of Science and Technology of Taiwan, R.O.C., under contract no. MOST 109-2313-B-005-007, and in part by the Joint Research Program of Taichung Veterans General Hospital and National Chi Nan University, Taiwan, R.O.C., under contract no. TCVGH-NCNU1047902.

\section{References}

1 N. R. Shanmugam, S. Muthukumar, and S. Prasad: Future Sci. 3 (2017) 4. https://doi.org/10.4155/fsoa-2017$\underline{0006}$

2 K. W. Guo: J. Appl. Biotechnol. Bioeng. 2 (2017) 5. https://doi.org/10.15406/jabb.2017.02.00046

3 J. Jiang, J. Pi, and J. Cai: Bioinorg. Chem. Appl. 2018 (2018) 5. https://doi.org/10.1155/2018/1062562

4 S. V. Gudkov, D. E. Burmistrov, D. A. Serov, M. B. Rebezov, A. A. Semenova, and A. B. Lisitsyn: Front. Phys. 9 (2021) 641481. https://doi.org/10.3389/fphy.2021.641481

5 V. Dincă, A. Mocanu, G. Isopencu, C. Busuioc, S. Brajnicov, A. Vlad, M. Icriverzi, A. Roseanu, M. Dinescu, M. Stroescu, A. Stoica-Guzun, and M. Suchea: Arab. J. Chem. 13 (2020) 3521. https://doi.org/10.1016/j. arabjc.2018.12.003

6 S. S. Elshama, M. E. Abdallah, and R. I. Abdel-Karim: Open Nanomed. J. 5 (2018) 16. https://doi. org/10.2174/1875933501805010016 
7 S. Sruthi, J. Ashtami, and P.V. Mohanan: Mater. Today Chem. 10 (2018) 175. https://doi.org/10.1016/j. mtchem.2018.09.008

8 K. Vasuki and R. Manimekalai: Heliyon 5 (2019) e02729. https://doi.org/10.1016/j.heliyon.2019.e02729

9 H. Beitollahi, S. Tajik, F. G. Nejada, and M. Safaei: J. Mater. Chem. B 8 (2020) 5826. https://doi.org/10.1039/ d0tb00569j

10 C. Maksoudian, N. Saffarzadeh, E. Hesemans, N. Dekoning, K. Buttiens, and S. J. Soenen: Nanoscale Adv. 2 (2020) 3734. https://doi.org/10.1039/d0na00286k

11 A. B. Moghaddam, M. Moniri, S. Azizi, R. A. Rahim, A. B. Ariff, M. Navaderi, and R. Mohamad: Genes 8 (2017) 281. https://doi.org/10.3390/genes8100281

12 I. Biswas, P. Roy, M. Majumder, S. Sau, and A. K. Chakraborty: Micro Nano Lett. 12 (2017) 474. https://doi. org/10.1049/mnl.2017.0114

13 A. J. Gimenez, G. Luna-Bárcenas, I. C. Sanchez, and J. M. Yánez-Limón: IEEE Sens J. 15 (2015) 1246. https:// doi.org/10.1109/JSEN.2014.2361780

14 S. Mun, H. C. Kim, H. U. Ko, L. Zhai, J. W. Kim, and J. Kim: Sci. Technol. Adv. Mater. 18 (2017) 437. https:// doi.org/10.1080/14686996.2017.1336642

15 B. L. da Silva, B. L.Caetano, B. G.Chiari-Andreo, R. Pietro, and L. A.Chiavacci: Colloids Surf. B 177 (2019) 440. https://doi.org/10.1016/j.colsurfb.2019.02.013

16 S.-W. Zhao, C.-R. Guo, Y.-Z. Hu, Y.-R. Guo, and Q.-J. Pan: Open Chem. 16 (2018) 9. https://doi.org/10.1515/ chem-2018-0006

17 S. L. Moulder, F. M. Yakes, S. K. Muthuswamy, R. Bianco, J. F. Simpson, and C. L. Arteaga: Cancer Res. 61 (2001) 24.

18 A. A. Dlugosz and S. H. Yuspa: Cancer Res. 51 (1991) 4677.

19 C.-P. Hsu, Y.-L. Wu, and J.-J. Lin: Med. Chem. S1:007 (2014) 1. https://doi.org/10.4172/2161-0444.S1-007

20 A. Garcia-Sanchez, A. G. Miranda-Diaz, and E. G. Cardona-Munoz: Oxid. Med. Cell. Longevity 2020 (2020) 2082145. https://doi.org/10.1155/2020/2082145

21 C. T. Ng, L. Q. Yong, M. P. Hande, C. N. Ong, L. E Yu, B. H. Bay, and G. H. Baeg: Int. J. Nanomed. 12 (2017) 1621. https://doi.org/10.2147/IJN.S124403

22 Y.-L. Wu, P.-Y. Hsu, C.-P. Hsu, and J.-J Lin: Biomed. Microdevices 14 (2012) 839. https://doi.org/10.1007/ $\underline{\text { s10544-012-9664-5 }}$

23 J. Notbohm, J. H. Kim, A. R. Asthagiri, and G. Ravichandran: Biophys. J. 102 (2012) 1323. https://doi. org/10.1016/j.bpj.2012.02.016

24 R. Punia, K. Raina, R.Agarwal, and R. P. Singh: PLoS One 12 (2017) e0182870. https://doi.org/10.1371/journal. pone. 0182870

25 S. Holmboe, P. L. Hansen, H. Thisgaard, I. Block, C. Muller, N. Langkjaer, P. F. Høilund-Carlsen, and B. B. Olsen: PLoS One 12 (2017) e0178286. https://doi.org/10.1371/journal.pone.0178286

\section{About the Authors}

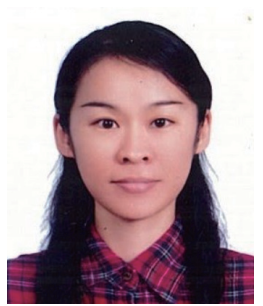

Su-Yu Liao received her B.S. degree from Providence University, Taiwan, in 1999 and her M.S. degree from Chaoyang University of Technology, Taiwan, in 2002. Since 2016, she has been a Ph.D. student in the Department of Electrical Engineering of National Chi Nan University, Taiwan. Her research interests are in tissue bioimpedance, biosensors, and chemistry.

(s105323904@mail1.ncnu.edu.tw)

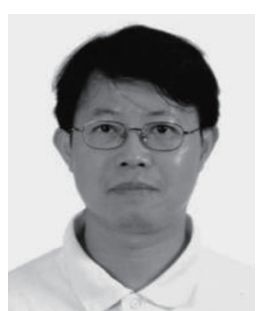

Jing-Jenn Lin received his Ph.D. degree in electrical engineering from National Taiwan University, Taipei, Taiwan, in 1992. He is currently a professor with the Department of Applied Materials and Optoelectronic Engineering, National Chi Nan University, Puli, Taiwan. His research interests include ultrathin gate-oxide reliability, biochemical sensors, and composite matrices. (cclin@ncnu.edu.tw) 


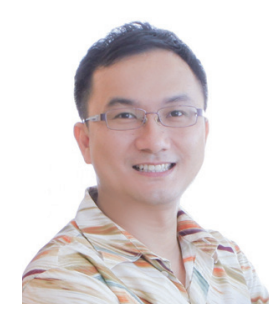

Congo Tak-Shing Ching received his Ph.D. degree in bioengineering from the University of Strathclyde, Glasgow, UK, in 2005. He is currently working at National Chung Hsing University, Taichung, Taiwan, as a professor of the Graduate Institute of Biomedical Engineering. His main research interests include biomedical instrumentation design, biosensors, tissue bioimpedance, biomedical electronics, biomedical optoelectronics, non-invasive medical diagnostics, and assistive technology. (tsching@nchu.edu.tw)

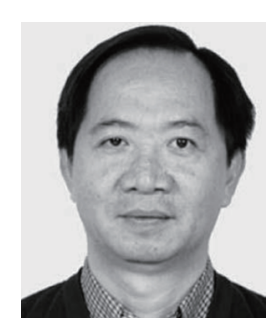

You-Lin Wu received his M.S. degree in electrical engineering from National Tsing Hua University, Taiwan, in 1984 and his Ph.D. degree in electrical engineering from National Taiwan University, Taiwan, in 1994. From 1995 to 1998, he was the manager of the Thin Film Department, Powerchip Semiconductor Corporation in Taiwan. Since 1998, he has been with the Department of Electrical Engineering, National Chi Nan University, where he is currently a professor. His research interests are in thin film materials and devices, resistive switching memory devices, and biochemical sensors. (ylwu@ncnu.edu.tw) 